\title{
ELABORAÇÃO DE JOGO EDUCACIONAL NA FARMACOLOGIA: A VALIDAÇÃO POR ESPECIALISTAS
}

\author{
Karla Meira Castro Zepponi ${ }^{1}$, Luzmarina Aparecida Doretto Braccialli ${ }^{2}$ e Osni Lázaro \\ Pinheiro $^{3}$ \\ 1,2Faculdade de Medicina de Marília (FAMEMA), São Paulo, Brasil, 'ka.zpp@hotmail.com; 'luzbra@terra.com.br \\ ${ }^{3}$ Faculdade de Medicina de Marília (FAMEMA), São Paulo, Brasil, ${ }^{3}$ osnilp@terra.com.br
}

\begin{abstract}
Resumo. A utilização de tecnologia educacional, por meio de estratégia lúdica, pode facilitar a aprendizagem dos estudantes. Construir um jogo para os estudantes do Curso Técnico de Farmácia de uma Instituição Pública de Ensino do Estado de São Paulo e o validar, por juizes da área da Educação e Farmacologia. Estudo qualitativo, de natureza descritiva e observacional, realizando a coleta de dados prospectiva, com quatro juízes da área de Educação e quatro de Farmacologia. $O$ juízes validaram o jogo, preenchendo os instrumentos, que foram analisados, readequados e submetidos novamente aos juízes, para nova validação. Os dados qualitativos foram organizados a partir de núcleos de sentido, e a análise foi de conteúdo, na modalidade temática. Emergiram três categorias: o papel do jogo e o papel do professor, a jogabilidade e a importância da aprendizagem significativa no jogo. A abordagem do jogo educativo pelos juízes foi relevante como estratégia lúdica e ferramenta de aprendizagem. Os juízes apontaram melhorias na construção do jogo para ensino em Farmacologia, apresentando conteúdo adequado para o ensino técnico, com temas da prática farmacêutica, articulando o conhecimento e o raciocínio e despertando o interesse do estudante.
\end{abstract}

Palavras-chave: Aprendizagem; Ensino; Jogo; Material Didático.

\section{ELABORATION OF EDUCATIONAL GAME IN PHARMACOLOGY: VALIDATION BY SPECIALISTS}

\begin{abstract}
The use of educational technological resources, through the development of a game, provides a playful strategy to facilitate student learning. Build an amusing game for students enrolled in the Technical Pharmacy course at a Public Teaching Institution in Sao Paulo State, and validate it by judges specialized in the areas of Education and Pharmacology. Descriptive and observational qualitative study, prospective data collection, with eight judges in the areas of Education and Pharmacology. These judges validated the game by filling in the instruments, which were analyzed, readjusted and submitted again to the judges, for further validation. The qualitative data were organized from the core of meanings and the analysis was by content, in the thematic modality. Three categories emerged: the role of the game and the role of the teacher, gameplay and the importance of meaningful learning in the game. The approach of the educational game by the judges was relevant as a ludic strategy and learning tool. The judges pointed out improvements in the construction of the game for teaching in Pharmacology, presenting a clear content, with context and real issues in the professional area, articulating knowledge, reasoning and arousing the student's interest.
\end{abstract}

Keywords: Learning; Education; Game; Teaching Materials.

\section{INTRODUÇÃO}

O Curso Técnico em Farmácia, no Brasil, tem como propósito a formação de um profissional que atenda às necessidades da sociedade. Nesse sentido, deve favorecer a formação de técnicos críticos, reflexivos e criativos, os quais possam realizar transformações na prática profissional em que estão inseridos (Conselho Federal de Farmácia, 2001). Dentre os 
conhecimentos básicos imprescindíveis para a formação do Técnico de Farmácia estão aqueles relacionados à terapêutica medicamentosa.

Para uma compreensão mais ampla da terapêutica medicamentosa, é importante que o Técnico de Farmácia tenha domínio de processos como seleção, produção, aquisição, programação, armazenagem, distribuição e dispensação de medicamentos. Este último se refere ao atendimento individualizado, com relação de confiança entre cliente e farmacêutico, que fará as orientações para o uso do medicamento (Angonesi \& Rennó, 2011). Além disso, conceitos básicos de Farmacologia, como farmacocinética, farmacodinâmica e manipulação das diversas formas farmacêuticas também são necessários (Rang, Ritter, Flower, \& Henderson, 2016).

Entretanto, a complexidade dos conhecimentos biológicos envolvidos em Farmacologia, relevantes para a compreensão do percurso do fármaco no organismo e também de sua ação nos diferentes órgãos, associados ao perfil do estudante de cursos de formação técnica em Farmácia, faz surgir um novo desafio para os educadores.

O desafio reside na escolha de uma estratégia educacional capaz de despertar o interesse de um jovem em processo de formação e que frequentemente ainda não possui uma ideia concreta da representatividade de seu futuro campo de atuação.

Nesse contexto, insere-se o professor, o qual, com criatividade e utilização de métodos de ensino e aprendizagem ativos, pode tornar mais prazerosa a aquisição dos conhecimentos de Farmacologia, importantes para a formação técnica, aproximando o conteúdo aprendido no âmbito escolar com a realidade do mercado de trabalho.

Os materiais didáticos utilizados para o ensino técnico nem sempre atingem as necessidades educativas dos estudantes dessa modalidade de ensino. Essa dificuldade faz com que os professores tenham de tornar aulas mais criativas e que despertem a atenção dos seus alunos. Para isso, podem empregar a diversidade dos recursos tecnológicos atualmente existentes, inclusive as informações do mundo virtual (Moran, 2000).

Essa nova abordagem pode tornar o estudante protagonista de sua formação, expondo seus conhecimentos como cidadão capacitado por suas experiências vividas. Por sua vez, o professor também precisa romper com os paradigmas do ensino tradicional, centrado na sua figura e caracterizado pela transmissão de conhecimentos (Assis, 2001). 
Novos caminhos mostram um melhor direcionamento, buscando o "aprender" e, para isso, não se pode partir do princípio de que o professor é o único detentor do conhecimento. A literatura disponível sobre formação docente está permeada de preocupações relativas à necessidade de melhoria no perfil desses profissionais. Além disso, esses professores precisam estar aptos a usar os melhores recursos disponíveis para fortalecer suas atividades educativas.

Nesse sentido, atividades lúdicas representam igualmente importantes recursos educacionais para a formação de estudantes de cursos técnicos, tornando as aulas mais interessantes e facilitando uma melhor assimilação dos conteúdos trabalhados em sala de aula. A literatura registra diversas experiências dessa natureza na Educação Profissional de Nível Técnico, como é o caso de uso de animações, jogos de tabuleiro e outros recursos existentes na Web (Justus \& Francisco, 2012).

Em um estudo realizado com estudantes do Curso Técnico de Farmácia que teve como objetivo melhorar o processo de ensino-aprendizagem na disciplina "Boas Práticas de Fabricação em Farmácia", o conteúdo programático foi problematizado após a exposição de um filme de desenho animado. Essa estratégia foi utilizada em virtude de os conteúdos da disciplina serem considerados pelos professores como de difícil assimilação para os estudantes. Além disso, geralmente os livros que abordam esses conteúdos são tidos como muito teóricos, com transcrição de normas e ausência de casos que promovam reflexões da prática profissional (Melo, Molino, Ribeiro, \& Romano-Lieber, 2017).

Nessa experiência, o emprego de desenho animado proporcionou a melhoria da qualidade das aulas, tornando-as mais atrativas e de fácil assimilação. As cenas do filme funcionaram como temas geradores de discussão, propiciaram a fixação dos conteúdos, além de terem proporcionado a discussão de situações reais para sala de aula. As avaliações dessa atividade mostraram que tal estratégia de ensino contribuiu para formação de um estudante crítico e comprometido com as implicações sociais e futuras tomadas de decisão, no âmbito profissional (Melo, Molino, Ribeiro, \& Romano-Lieber, 2017).

O universo lúdico manifesta um caráter irreverente, imaginativo e criativo de relações sociais, e a disputa está presente nas experiências da vida cotidiana. A natureza lúdica não está restrita somente a jogos: acontece nas artes, nas organizações e até mesmo em religiões e relacionamentos nem sempre explícitos (Pires, Gottems, \& Fonseca, 2017). O jogo permeia as regras e sua subversão, apreensão e descontração, assim como invade o real e o 
imaginário, aspectos envolvidos nas ações humanas, de sorte a trazer conexão com a realidade (Pires, Gottems, \& Fonseca, 2017). O jogo de tabuleiro apresenta concepção lúdica, podendo ser responsável pelo desenvolvimento do pensamento crítico que foge do conhecimento unidirectional (Fornari \& Fonseca, 2019). A aprendizagem pode ser concretizadas por meio de cursos, oficinas, palestras, grupos de estudo, jogos de simulação, jogos educativos eletrônicos com acessos em smartphone, tablet e computadores e jogos de tabuleiro, desde que tenham fins didáticos (Fornari \& Fonseca, 2019; Serafim, Silva, Alcântara, \& Queiroz, 2019).

Tendo em vista as premissas apresentadas, a construção de um tabuleiro com perguntas e respostas direcionadas ao trabalho dos conteúdos da disciplina de Farmacologia, voltada ao Ensino Técnico de Farmácia, poderá promover uma atividade lúdica para a aquisição e a troca de conhecimentos entre os participantes.

Nesse contexto, o presente estudo tem como objetivo construir e validar um jogo educativo sobre Farmacologia para o Ensino Técnico de Farmácia.

\section{METODOLOGIA}

Trata-se de uma investigação de natureza descritiva e observacional, com coleta de dados de maneira prospectiva. O estudo foi aprovado pelo Comitê de Ética em Pesquisa Envolvendo Seres Humanos de um Instituição Pública do Estado de São Paulo, Brasil (CAAE 03948318.4.00005413). Este trabalho envolveu a validação de um jogo de tabuleiro desenvolvido pelos autores desta pesquisa, com a utilização de conteúdos de Farmacologia.

Em um primeiro momento, o grupo de pesquisa responsável por este projeto discutiu sobre as melhores opções de jogos a serem usados. Foram feitas buscas na literatura científica, a fim de identificar as características desejáveis para a elaboração de jogos educativos. Nesse sentido, o jogo foi elaborado com estruturas que estimulavam o processo de ensino e aprendizagem, de forma lúdica e pedagógica. O formato, as cores, as imagens que conferem descontração e interatividade, assim como os conteúdos e as regras visavam a uma coerência para facilitar a organização e a compreensão do jogo, proporcionando ao aluno participar espontaneamente da atividade (Serafim, Silva, Alcântara, \& Queiroz, 2019; Ventura, Souza, \& Moulin, 2016). 
O conteúdo de Farmacologia foi abordado em linguagem condizente com as necessidades de estudantes de curso técnico, com clareza na redação, articulação de situações vivenciadas na prática profissional do técnico farmacêutico, propiciando o raciocínio dos estudantes.

O tabuleiro foi impresso em madeira com fibra de média densidade (MDF) e corte a laser. As cartas coloridas foram impressas em gráficas, enquanto os pinos foram feitos em impressora 3D. Os conteúdos foram desenvolvidos com a abordagem de situações possíveis do cotidiano de uma farmácia, por meio do conteúdo aprendido em sala de aula, como a farmacodinâmica, a farmacocinética e as interações medicamentosas.

As cartas do jogo com perguntas e respostas contemplaram trinta questões de Farmacologia, no formato de múltipla escolha. Foi também preparado um manual contendo todas as regras do jogo, as informações das cartas-bônus que poderiam ajudar o estudante, no decorrer do jogo, a quantidade de participantes e a forma de jogar.

Após a confecção do jogo de tabuleiro, foi realizada a validação desse material lúdico/didático por um painel composto por dois grupos de juízes com expertises em Farmacologia $(n=4)$ e Educação $(n=4)$.

Os juízes da área de Farmacologia receberam um questionário contendo critérios de avaliação relacionados ao "Objetivo/Conteúdo" e outros ligados à "Relevância do jogo". Por sua vez, os juízes da área da Educação receberam um questionário contemplando os critérios para avaliação da "Estrutura/Organização" e "Ludicidade do jogo" (Pires, Gottems, Silva, Carvalho, Melo \& Fonseca, 2015).

Todos os questionários possuíam um campo aberto, a fim de que os juízes manifestassem livremente suas opiniões sobre os critérios de avaliação abordados. As identificações dos juízes avaliadores foram feitas por códigos alfanuméricos, “J” de 1 a 8.

Os dados qualitativos provenientes dos campos abertos foram avaliados por meio de técnica de análise de conteúdo, modalidade temática. A análise de conteúdo preconiza a cientificidade, é uma técnica derivada das caracteristícas citadas com frequência no conteúdo, examinando comunicações para a obtenção de indicadores que permitam a inferência dos conteúdos das mensagens (Bardin, 2012; Minayo, Deslandes, \& Gomes, 2016). A análise temática compreende relações entre palavras e frases ou resumo e, através delas, trabalha a descoberta de núcleos de sentidos, nos quais a frequência com que as palavras ou frases se 
repetem podem significar algo. A metodologia deste estudo envolveu uma leitura compreensiva do material, a forma de classificação das palavras ou frases que conotam o mesmo sentido, seguidas de uma categorização e, a partir de então, foram definidos os núcleos de sentido (Minayo, Deslandes, \& Gomes, 2016).

O uso dessa técnica favoreceu uma interpretação das descrições emitidas pelos juízes, com maior objetividade.

A análise qualitativa é composta de estruturas como a vivência, senso comum e ação; esses pontos culminam na análise, trazendo compreensão, interpretação e dialeto (Minayo, 2012). Enfoca a complexidade da subjetividade, levando em conta as diferentes formas de interpretação de cada indivíduo, vistas por diferentes olhares.

As experiências e reflexões vividas por cada um culminam em uma interpretação única, a qual depende da vivência diante de cada fato ocorrido e absorvido. O senso comum advém do conhecimento adquirido por meio das experiências e vivências que conferem ao sujeito a possibilidade do agir, embasado em seus valores e pensamentos. A compreensão vem da junção desses fatores, propiciando um entendimento singular de cada situação, podendo trazer discordância diante de um fato analisado por vários indivíduos (Minayo, 2012).

A construção do material teve por finalidade contemplar os detalhes de informações, sem contaminações de interpretações precipitadas. A intenção é compilar os achados, seguindo uma ordenação (esse material foi ordenado por avaliações), depois classificações (critério por apontamentos positivo e negativos), for fim, a definição das temáticas com apontamentos relevantes (Minayo, 2014; Moreira, Higa, Braccialli, Moraes, Tonhom, \& Pinheiro, 2019). Ora, sem desprezar os detalhes, permeando o significado que os comentários expressam, o sentido da fala e o contexto empírico, a análise acontece após a compreensão profunda, embasada na teorização, na intenção de produzir um material fidedigno, com informações concisas e fiéis (Minayo, 2012). 


\section{RESULTADOS E DISCUSSÃO}

$\mathrm{Na}$ análise qualitativa, a formação essencialmente técnica referente aos dados obtidos nos campos abertos, agrupados por ordem, classificação e análise, emergiram dos depoimentos dos juízes, por intermédio de três categorias: o papel do jogo e o papel do professor envolvendo a fácil compreensão, estratégias de raciocínio e uma linguagem adequada, o uso de intencionalidade, o jogo como ferramenta pedagógica, o incentivo à busca de conhecimento, a sistematização do professor, a relação intencional do processo de ensino e aprendizagem, o tema e o objetivo; a jogabilidade - que compreende a confiança, a satisfação e a motivação do estudante pelo jogo, a construção do conhecimento, a organização, o respeito, a disciplina, a cooperação, a resolução com soluções, as regras claras, a dinamicidade e a diversão; e a importância da aprendizagem significativa no jogo - a qual aborda a relevância do conteúdo, o conteúdo prévio, o conteúdo associado com a realidade da profissão, os exemplos reais com conteúdo teórico, a interação com questões desafiadoras; não privilegia a memorização, porém, faz circular saberes, a autoavaliação, a aprendizagem divertida e o aprendizado consciente (Serafim, Silva, Alcântara, \& Queiroz, 2019).

\subsection{Papel do jogo e o papel do professor}

A intencionalidade do jogo como ferramenta de aprendizagem, com linguagem adequada e cuidados na elaboração de regras, objetivo e tema do conteúdo, traz uma melhor compreensão, tendo sido percebida pelas colocações dos juízes na avaliação:

Acredito que o título poderia ser complementado com um subtítulo, especificando qual o conhecimento sobre Farmacologia este jogo abordará. (J2)

Objetivo será alcançado se o estudante/jogador responder corretamente as questões e/ou se tiver sorte, pois se um jogador tirar com maior frequência que os demais as cartas com "ir a biblioteca", "ir para praia" será retardado no percurso, não por desconhecer o conteúdo, mas por falta de "sorte" mas o jogo torna possivel chegar ao objetivo. (J4)

O jogo é simples e de fácil compreensão. (J5)

A estratégia em jogo para o ensino desse conteúdo é muito interessante. (J6)

Trazer o tema no Manual. (J7)

Os comentários dos juízes mostraram o papel do jogo, no objetivo proposto, que é fomentar o conhecimento por meio do universo lúdico, procurando o raciocínio em situações do âmbito profissional do técnico em Farmácia com o conteúdo de Farmacologia que leve à 
aprendizagem. Nesse sentido, a construção e a busca do conhecimento, através de metodologias ativas, no caso, os jogos didáticos, contribuem para o despertar da prática da educação em saúde e seu desempenho, relacionados às habilidades e atitudes por intermédio da criticidade e reflexão que o método proporciona (Limberger, 2013).

O uso da metodologia ativa aproxima estudante e professor, resultando na aprendizagem; com efeito, o professor é um mediador que alavanca a motivação do estudante, por meio da construção do conhecimento com os jogos didáticos, pois o anseio de vencer gera desafios que possibilitam a sensação de bem-estar (Ventura, Souza, \& Moulin, 2016).

O professor tem um importante papel de mediador, direcionando o estudante diante dos saberes e extraindo da melhor forma as estruturas cognitivas em associação com novos conceitos, através de sistematização:

Para o professor precisa estar claro o uso e a intencionalidade como ferramentas pedagógicas, o tipo de avaliação (diagnóstica, somativa, formativa) e quais indicadores de avaliação são os critérios, isto é, o que estará avaliando no estudante (conhecimentos, habilidades, atitudes e valores). (J1)

Acredito que isso se resolverá com a explanação do professor sobre o tema, tendo em vista que o jogo é uma ferramenta de aprendizagem e o professor é o mediador do processo de ensino aprendizagem. (J5)

O professor dispor de métodos variados é um processo valioso, que fomenta interesse, dinamismo; se exige uma didática mais elaborada, se requer um trabalho maior do professor, apresenta um significativo retorno de qualidade, deixando para trás os métodos passados (Ventura, Souza, \& Moulin, 2016)

\subsection{Jogabilidade}

Trabalhar a disciplina, no contexto do jogo, marca a referência do comportamento ético e moral perante os colegas, contrário a comportamentos estáticos e tímidos; assim, busca-se o comportamento descontraído e competitivo das brincadeiras, o qual faz parte da ludicidade.

Quanto à disciplina (questão 12) é possível promover a disciplina, no entanto, em se tratando de jogos que podem estimular um caráter competitivo pode tornar-se difícil de manter a organização, respeito e disciplina dos estudantes. (J1) 
Concordo que o jogo possa propiciar cooperação, mas não acredito ser salutar ao aprendizado e estímulo à competição, a não ser que essa seja bem discutida com os estudantes. Material excelente apresentação impecável parabéns. (J2)

Não compreendo que as atividades voltadas para a aprendizagem tenham relação com o comportamento no sentido da disciplina. Apenas de competição. $O$ auxiliar será apenas leitor das perguntas, não há cooperação no sentido de interatividade, acredito que esse tipo de atividade possa ser dinâmico e agitado, que não são comportamentos próximos de estudantes interagindo com situações desafiadoras, isso não é indisciplina. (J4)

A aprendizagem pelos jogos fixa limites usados na relação social, ensejando encontros de pessoas diferentes que se organizam a partir de regras, culminando na disciplina, lealdade e honestidade. O mundo lúdico prepara o indivíduo para a sociedade, com regras coletivas, determinando limites entre a vida real e a lúdica (Faeti \& Calsa, 2015).

A competitividade comporta diferenças entre resignação e significação dos papéis ocupados no jogo, favorecendo um ambiente de competição, o qual, por sua vez, estabelece relações de cooperação (Faeti \& Calsa, 2015). A competição caminha junto com a cooperação, na ludicidade, é necessária para a interação dos estudantes e permeia situações socioculturais, significando valores que integrarão a vida do estudante (Faeti \& Calsa, 2015). As estruturas, reunindo cor e alegria, são coerentes para facilitar a compreensão do jogo com a organização e proporcionam ao estudante participar espontaneamente das aulas, porém, o esclarecimento das regras se faz necessário, para o bom andamento do jogo (Ventura, Souza, \& Moulin, 2016).

Quando as regras não estão claras, causam questionamentos, como os citados abaixo:

A maior parte das regras está clara, mas não como jogar, está um pouco confuso sobre as cartas bônus, três ficam com o jogador e as outras no monte? Em qual momento ele pegará estas? (J2)

Em "como jogar" poderia explicitar que o jogo inicia com cada jogador recebendo uma carta "pulo", uma carta "exclua uma resposta" e uma carta "estudante", não fica claro que essas cartas devem ser as únicas de bônus do início. (J4)

Pensei uma alternativa ao jogo que seria a inclusão de cartas específicas para o estudante/jogador que vai até a biblioteca essas cartas poderiam ter resumos que o jogador pudesse acessar. (J5) 
Elaborar as regras de modo claro é primordial para o bom andamento do jogo; por isso, as sugestões nos campos abertos contribuíram significativamente para a melhoria do jogo, conforme relato dos juízes:

A questão "vá para a biblioteca" ficou melhor. Da forma como estava parecia que ir a biblioteca era uma punição, devemos sempre incentivar à busca ao conhecimento. O estudante tem que associar o ir à biblioteca como uma forma de oportunidade de melhoria. (J5)

\subsection{A importância da aprendizagem significativa no jogo}

A organização e a estrutura dos jogos tiveram apontamentos positivos, de sorte que os juízes acreditam que o jogo auxiliará o pesquisador a fazer uma melhor avaliação do conhecimento aprendido pelos estudantes. Os materiais utilizados em sala de aula, para aprendizagem, servem como ponte entre o que se sabe e o que se planeja ensinar, levando ao raciocínio do estudante e alcançando a teoria da assimilação (Darroz, 2018).

O ponto mais importante de todo o jogo é o conteúdo; logo, caso as estratégias, regras, estruturas estejam adequadas e o conteúdo não for apropriado e acessível ao patamar de conhecimento do ensino técnico, a proposta não terá funcionalidade. Os juízes fizeram considerações cruciais para a melhoria da proposta de aprendizagem e apontaram cuidados nas questões de memorização e a necessidade de reestruturação do conteúdo:

Para esse jogo sugiro um moderador, que poderá ser um estudante. (J3)

Caso as questões sejam muito fáceis, não haverá interesse por muito tempo, poderá, ou não, despertar interesse do ponto de vista visual ou de conteúdo. (J4)

Algumas perguntas presentes no jogo das cartas do tabuleiro eu reavaliaria o conteúdo, cartas com possibilidade de respostas ambíguas em outras não concordei com a resposta assinalada como correta, também observei que algumas cartas a pergunta estão com elaboração um pouco confusa. (J5)

Colocar mais situações problema. Existem alguns pontos em relação às perguntas e respostas apresentando imprecisões, acredito que o jogo insiste em trabalhar questões não essenciais para o cotidiano, o conteúdo está sendo bem trabalhado, apenas questões conceituais ao meu ver não são tão pertinentes. (J6)

Várias questões são respondidas com memória, penso que as questões apenas de memorização podem não despertar tanto interesse. (J7)

Não utilizar nomes comerciais, via intravenosa e endovenosa são antônimos, os conteúdos e respostas estão semelhantes, considerando o número reduzido de apresentações de medicamentos por via retal disponíveis no elenco de medicamentos padronizados nas 
unidades hospitalares, consideraria alterar a opção de resposta para somente via endovenosa parenteral. (J8)

Nas considerações dos juízes, o cuidado para articular o conteúdo internalizado ao já conhecido é imprescindível. Nessa perspectiva, os conceitos pré-existentes servem como âncoras para que as novas informações se integrem ao conhecimento, o qual caracteriza a aprendizagem significativa (Darroz, 2018).

A importância do conteúdo é abordada nas descrições citadas pelos juízes:

Gostei muito e me vejo usando em sala de aula, visual amigável e perguntas objetivas. (J1)

Favorece a fixação do conteúdo. (J3)

Quando o estudante responde perguntas está testando seus saberes e, quando erra e sabe porque errou de forma consciente terá oportunidade de aprender, as questões que ilustram uma situação levam ao raciocínio, as que são objetivas de resposta direta são apenas de memorização. (J4)

Ocorre uma mescla interessante desses exemplos reais com conteúdos teóricos, o jogo contém informações importantes e cruciais, aborda adequadamente os conteúdos da disciplina, proporciona ao estudante um meio divertido e eficaz de aprendizado, as perguntas são elaboradas com exemplos de pacientes ou situações possíveis de acontecerem no exercício de sua futura profissão. (J5)

O jogo é bem interativo e traz questões relevantes quanto ao conteúdo de Farmacologia. (J7)

O conteúdo mal elaborado pode induzir ao erro da aprendizagem; por conseguinte, o pesquisador deve trabalhar o conteúdo de forma clara, a fim de minimizar a indução ao erro, embora o erro seja considerado necessário para se alcançar a resposta certa (Justus \& Francisco, 2012).

Os conteúdos abordados foram estabelecidos dentro da ementa do plano de curso, associado às necessidades do cotidiano do profissional técnico farmacêutico, com o cuidado de aproveitar informações lógicas e articular uma informação com outra, apresentando pontos essenciais (Araujo \& Freitas, 2017; Silva, 2002).

Diante da avaliação e das pontuações dos juízes, fica evidente a necessidade de elaborar melhor as questões com conteúdo da Farmacologia (farmacocinética e farmacodinâmica e interações medicamentosas), propiciando consonância deste com o cotidiano e levando em conta os diversos níveis de saberes que há em sala de aula. 
Assim, possibilita progresso ao estudante que tem facilidade e agrega nas informações dos que têm dificuldade na absorção do conteúdo apresentado e com cautela, para não desestimulá-los.

Os comentários dos juízes apontam a possibilidade da autoavaliação dos estudantes, que pode trazer motivação, ao perceberem suas mudanças nos saberes:

Concordo que estarão fazendo circular saberes e se autoavaliando e, por isso, tendem a aprender de maneira divertida, um aspecto interessante para aprendizagem, possibilita que $o$ estudante se veja diante dos seus saberes e não saberes, o autoconhecimento para o professor acompanhar o desempenho dos estudantes. (J4)

Os jogos são alternativas para preencher lacunas de transmissão-recepção de conhecimento, favorecendo os conhecimentos adquiridos pelos estudantes e podendo proporcionar uma autoavaliação (Ventura, Souza, \& Moulin, 2016).

\section{CONCLUSÕES}

As descrições presentes nos relatos enfatizaram a relevância de elaborar um conteúdo claro, capaz de associar o contexto do conteúdo escolar com assuntos reais, dentro da área profissional. Também fazem uma ancoragem entre vínculo e imersão dos estudantes e se tornam um ambiente favorável para absorver e articular conhecimento, apontando a viabilidade do ensino de Farmacologia por meio de um jogo o qual aproxima conhecimento e raciocínio, despertando o interesse do estudante.

O estudo oportunizou uma visão da abordagem do material que foi estudado, classificado e categorizado, a qual fomentou uma análise minuciosa, por meio dos núcleos de sentidos, ajudando a verificar um maior entendimento dos apontamentos dos juízes, os quais agregaram melhorias na proposta do jogo para ensino em Farmacologia.

Foi possível perceber que a intencionalidade do professor, como mediador, confere ao estudante uma aprendizagem voltada para o raciocínio e a reflexão, fugindo do ensino unidirecional e o tornando protagonista dentro da sala de aula.

O desenvolvimento de estratégia lúdica com objetivo definido, conteúdos adequados e regras claras permite um envolvimento entre os estudantes, com atitudes de cooperação, respeito, disciplina, integração, ensejando a construção do conhecimento e trazendo como resultado a satisfação e a motivação pela aprendizagem. 
A importância dos jogos educativos, dentro do contexto da Farmacologia, associando conhecimentos prévios e novas informações, pode proporcionar uma aprendizagem significativa.

\section{REFERÊNCIAS}

Angonesi, D., \& Rennó, M. U. P. (2011). Dispensação farmacêutica: proposta de um modelo para a prática. Ciência \& Saúde Coletiva, 16(9), 3883-3891.

Araujo, N. M. S., \& Freitas, F. R. R. (2017). Protocolo de avaliação de softwares pedagógicos: analisando um jogo educacional digital para ensino de língua portuguesa. Alfa, 61(2), 381-408.

Assis, M. (2001). Uma nova sensibilidade nas práticas de saúde. Interface - Comunicação, Saúde, Educação, 5(8), 139-140.

Bardin, L. (2012). Análise de conteúdo. São Paulo: Edições 70.

Conselho Federal de Farmácia. (2001). Resolução n. 365 de 2 de outubro de 2001. Dispõe sobre a assistência técnica farmacêutica em distribuidoras, representantes, importadoras e exportadoras de medicamentos, insumos farmacêuticos e correlatos. Brasília (DF): Diário Oficial da União. Seção 1, p. 324.

Darroz, L. M. (2018). Aprendizagem significativa: a teoria de David Ausubel. Espaço Pedagógico, 25(2), 577-580.

Faeti, P. V., \& Calsa, G. C. (2015). Jogo, competição e cooperação: articulando saberes. XII Congresso Nacional de Educação, Pontifícia Universidade Católica do Paraná (PUCPR).

Fornari, L. F., \& Fonseca, R. M. G. S. d. (2019). Prevenção e enfrentamento da violência de gênero por meio de jogos educativos: uma revisão de escopo. RISTI - Revista Ibérica de Sistemas e Tecnologias de Informação, 33, 78-93.

Justus, J. F. C., \& Francisco, A. C. (2012). Detetive da saúde: a contribuição de um jogo de tabuleiro para o ensino e a aprendizagem na área da saúde. Revista Brasileira de Ensino de Ciência e Tecnologia, 5, 101-122.

Limberger, J. B. (2013). Metodologias ativas de ensino-aprendizagem para educação farmacêutica: relato de experiência. Interface - Comunicação, Saúde, Educação, 17(47), 969-975.

Melo, D. O., Molino, C. G. R. C., Ribeiro, E., \& Romano-Lieber, N. S. (2017). Capacitação e intervenções de técnicos de farmácia na dispensação de medicamentos em Atenção Primária à Saúde. Ciência \& Saúde Coletiva, 22(1), 261-268.

Minayo, M. C. S. (2012). Análise qualitativa: teoria, passos e fidedignidade. Ciência \& Saúde Coletiva, 17(3), 623626.

Minayo, M. C. S. (2014). O desafio do conhecimento: pesquisa qualitativa em saúde. (14ª ed). São Paulo: Hucitec.

Minayo, M. C. S., Deslandes, S. F., \& Gomes, R. (2016). Pesquisa social; teoria, método e criatividade. (1 $1^{\mathrm{a}}$ ed). Petrópolis: Vozes.

Moran, J. M. (2000). Mudar a forma de ensinar e de aprender com tecnologias. Revista Interação - Estudos e Pesquisa em Psicologia, 9, 57-72.

Moreira, H. M., Higa, E. F. R., Braccialli, L. A. D., Moraes, M. A. A., Tonhom, S. F. R., \& Pinheiro, O. L. (2019). O desafio da avaliação no internato da medicina. In Paper presented at the Atas do $8^{\circ}$ Congresso IberoAmericano em Investigação Qualitativa, Lisboa Portugal.

Pires, M. R. G. M., Gottems, L. B. D., \& Fonseca, R. M. G. S. (2017). Recriar-se lúdico no desenvolvimento de jogos na saúde: referências teórico-metodológicas à produção de subjetividades críticas. Texto \& Contexto 
- Enfermagem, 26(4).

Pires, M. R. G. M., Gottems, L. B. D., Silva, L. V. S., Carvalho, P. A., Melo, G. F., \& Fonseca, R. M. G. S. (2015). Desenvolvimento e validação de instrumento para avaliar a ludicidade de jogos em saúde. Revista da Escola de Enfermagem da USP, 49(6), 981-990.

Rang, H. P., Ritter, J. M., Flower, R. J., \& Henderson, G. (2016). Farmacologia. (8a ed). São Paulo: Koogan.

Serafim, A. R. R. d. M., Silva, A. N. S., Alcântara, C. M. d., \& Queiroz, M. V. O. (2019). Construção de serious games para adolescentes com diabetes mellitus tipo 1. Acta Paulista de Enfermagem, 32(4), 374-381.

Silva, C. R. (2002). MAEP: um método ergopedagógico interativo de avaliação para produtod educacionais informatizados. (Tese de Doutorado não publicada), Universidade Federal de Santa Catarina, Florianópolis. Recuperado de https://repositorio.ufsc.br/bitstream/handle/123456789/84254/182757.pdf?sequence=1.

Ventura, J. P., Souza, S. K., \& Moulin, M. M. (2016). A importância do uso de jogos didáticos como método facilitador de aprendizagem. In Paper presented at the XX Encontro Latino Americano de Iniciação Científica, XVI Encontro Latino Americano de Pós-Graduação e VI Encontro de Iniciação à Docência, Universidade do Vale do Paraíba. 